Document downloaded from:

http://hdl.handle.net/10251/62752

This paper must be cited as:

Jose Antonio; Mas Verdú, F.; Norat (2015). Knowledge, Promotional Events, and the Contribution of Clustering to Innovation. Journal of Promotion Management. 21:504-515. doi:10.1080/10496491.2015.1051407.

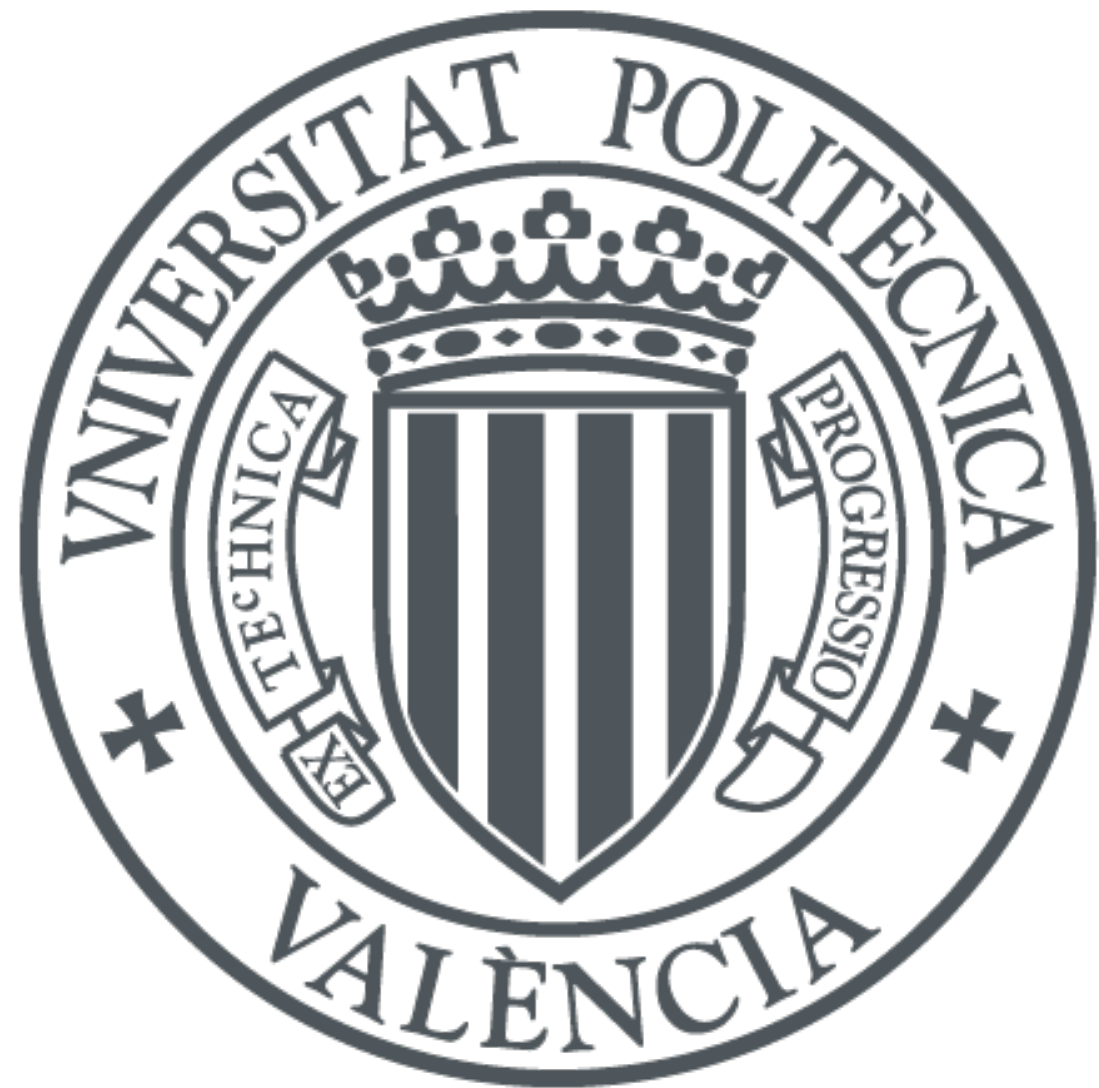

The final publication is available at

http://dx.doi.org/10.1080/10496491.2015.1051407

Copyright Taylor \& Francis (Routledge): SSH Titles

Additional Information

This is an author's accepted manuscript of an article published in: "Journal of Promotion Management"; Volume 21, Issue 4, 2015; copyright Taylor \& Francis; available online at: http://dx.doi.org/10.1080/10496491.2015.1051407 


\title{
PAPER ENVIADO
}

\section{Knowledge, promotional events and the contribution of clustering to}

\section{innovation}

\author{
José Antonio Belso-Martínez* (Universidad Miguel Hernández) ${ }^{1}$ \\ Francisco Más-Verdú (Universitat Politécnica de Valencia) \\ Norat Roig-Tierno (Universitat Politécnica de Valencia) \\ *jbelso@umh.es
}

\begin{abstract}
This research provides insight on the mechanisms through which knowledge acquired through promotial events and through spatial co-location simultaneously sustains firm's innovation. Applying the concept of temporary clusters to promotional events, we simultaneously test how internal resources' mediating effect and promotional events' moderating role affect innovation in clusters. Regression analyses with non-parametric bootstrapping and a large sample of Spanish clusters confirm the synergies derived from the combination of internal resources, local relationships, and complementary foreign events. Although extra-cluster linkages increase this effect, synergies creation requires attendance to international exhibitions or conventions. Valuable implications for practioners and policy makers are dicussed.
\end{abstract}

Keywords: Clusters, knowlege, networks, promotional events, Spain

1 The authors gratefully acknowledge the financial support provided by the Spanish Ministry of Economy and Competitiveness (ECO2010-20557). The authors would also like to thank participants in the 52nd European Regional Science Congress in Bratislava for valuable comments, particularly regarding additional controls for improving the robustness of the statistical results. 
JEL code: L14, L29

\section{Introduction}

Promotional events such as trade shows and fairs are powerful tools that can make the difference between the success and failure of the internationalization process or the introduction of new products (Palumbo \& Herbig, 2002). By participating, firms always aspire to increase company's presence in the market, promote product reputation, and launch new products services in the market. However, the nature and objectives of exhibitions and trade shows change over time and product life cycle (Tanner \& Chonko, 2002). In this vein, the growing intangibility of the outcomes of these marketing events hinders a reliable evaluation their effectiveness (Wood, 2009).

Knowledge flows, networking, customer integration and relationship attributes are crucial aspects in determining the success of trade fairs, even of virtual trade fairs (Geigenmüller, 2010). Meetings allow participants to build supraregional interorganizational architectures and access to rich information flows through different forms of interaction. For instance, buyers' reactions to products on display may provide in-depth knowledge of markets and end-customers, whichmay help further product developments. Therefore, learning activities growing out of trade shows nowadays represent important avenues for the creation of advantages which should be a main objective of these temporary meetings (Ling-yee, 2006).

During decades, academics and policy makers have taken for granted the homogeneity and the positive effect of spatial clustering on innovation. In this vein, intra-cluster cooperation fosters innovation performance by triggering collective learning processes (Asheim \& Isaksen, 2002). However, clustered firms may not engage and benefit from external resources to the same extent. Each firm's specific assets, particularly the absorptive capacity (Cohen \& Levinthal, 1990), determine its ability to 
access, absorb, and employ knowledge outside firm's boundaries. Furthermore, firms presenting solid resources are more prone to establish valuable relationships with other units (Giuliani \& Bell, 2005). The corollary is inmediate, clustered firms may present asymetries of resources and linkages capable of generating notable differences in terms of innovation performace. The stronger the firm's resources and absorptive capacity are, the higher their probability to acquire and apply external knowledge to achieve an outstanding innovation outcome compared to their counterparts..

Deeper analysis of these industrial systems highlights not only their growing heterogeneity, but also the increasing permeability of their boundaries. For example, positive and negative effects derived from co-location coexist in clusters. Access to non-local repositories of knowledge enables firms to avoid undesirable phenomena, by providing new knowledge necessary for substantial innovations (Bathelt et al., 2004; Wolfe \& Gertler, 2004). Institutions and leading firms may act as brokers between local firms and extra-cluster repositories of knowledge, capturing and elaborating fresh knowledge that is later diffused inside the industrial system. Firms can also develop their own extra-cluster relationships by establishing contacts with actors located outside the cluster boundaries through exhibitions or trade shows. Recent research views these events as relational spaces in which countless actors spontaneously interact and learn (Rinallo \& Golfetto, 2011). However, these mechanisms for knowledge transfer do not offer equal reciprocity, trust, understanding and serendipity.

The 'relational turn' in economic geography opens for new understandings of how proximity still matters for knowledge exchange. Admitting the fuzzy nature of the concept (Markussen, 1996), proximity means "being close to something" either from a geographical (physical) and/or a relational dimension (Lagendijk \& Lorentzen, 2007). Both spatial co-location and social interactions facilitate knowledge transfers and have a 
positive effect on performance (Boschma, 2005). However, continuous interactions owing to geographical co-location are not always necessary for innovation. This idea has underpinned the widespread belief in the importance of spatial proximity (Rychen \& Zimmermann, 2008). Nowadays, the need for spatial proximity can be circumscribed to certain stages of the process of production, research, or development (Rallet, 2008). As recent research evidences, geographical proximity remains crucial for knowledge transfers, but it may not imply permanent co-location. Temporary proximity implies non-localized and sporadic interactions, capable of generating valuable knowledge transfers (even fine-grained) that ensure inflows of knowledge and consequently retain the potential for innovation through recombination (Ramirez-Pasillas 2008; Torre, 2008). Even when co-location is temporary, spatial proximity during exhibitions or trade shows multiplies the occasions to meet and contact, using both formal and informal channels. Consequently, trade shows and exhibitions behave like these temporary clusters where knowledge transfers and diverse synergies emerge (Bathelt \& Schuldt, 2008).

This distinction between permanent proximity and temporary proximity has challenged the territorialized innovation theories that highlight the functional role of local capabilities and benefits of spatial proximity between interacting parties. Consequently, an intense debate among researchers has emerged, as the relevance of these temporary forms of proximity is emphasized at the expense of the traditional contribution of permanent co-location. While non-local knowledge obtained through these temporary forms of proximity sustains the innovation trajectory; the importance of the industrial system is limited to the supply of labour and the support of local institutions (Lorentzen, 2007). This situation relegates the industrial system's role as source of knowledge and innovation. In other words, geographical proximity remains 
crucial for knowledge transfers, but short or medium term interactions may suffice to exchange the information needed for cooperation (Rallet, 2008).

This study aims to contribute to this debate by further analysing the mechanisms through which both permanent and temporary proximity affect innovation performance. Considering Ramirez-Pasillas' (2010) findings, this research overcomes relevant limitations by simultaneously considering the interconnectivity of local networking activities and temporary geographical proximity. The literature review (RamirezPasillas, 2010; Rinallo and Golfetto, 2011)leads to expect that, in firms with high levels temporary co-location (trade shows), intra-cluster relationships might be more likely to foster innovation through internal resources; transitory interactions exercise an amplifying effect because of addditional opportunities for valuable information sharing and synergies. In other words, this research aims to confirm that internal resources mediate the effect of vertical relationships on innovation performance as a function of the underlying level of temporary proximity.

Figure 1 here.

In doing so, the study not only considers the importance of firm's resources and interactions in the process of knowledge transfers and innovation (Autant-Bernard et al., 2007; McCann \& Folta, 2011); at the same time, it recognizes knowledge and innovation processes' complexity,so thatmonotonic relationships and direct effects cannot always explain them. Hence, by using a firm-level data from a footwear cluster and a moderated mediation model, this study expands pre-published literature that focuses on moderating effects or mediating effects, relegating the jointly analysis of both phenomena. The following sections describe the study setting, dicuss the main findings, and present conclusions and implications. 


\section{The study setting}

\subsection{Data and sample issues}

The Spanish footwear industry is characterized by the prevalence of geographically agglomerated SMEs that show a high specialization in concrete stages of the production process. The Vinalopo cluster is the largest agglomeration accounting for over $60 \%$ of the national production, and has been identified as an industrial district (e.g. Giner \& Santa María, 2002). This vertically disintegrated structure shows collective efficiency and innovative dynamics. Thus the existence of a solid auxiliary industry resultng from spin-off processes has facilitated the implantation of sophisticated business models based on branding or design. Finally, universities, research centers, or associations located inside the cluster boundaries provide specialized services, promote an atmosphere of trust crucial to inter-firm cooperation, and facilitate the access of local actors to extra-cluster repositories of knowledge.

Data for this research was collected in the Vinalopo cluster using a two stage methodology. Through the initial stage, 12 semi-structured questionnaires and face-toface interviews provided primary data about the industry to elaborate the questionnaire and enhance results discussion. In the second stage, after testing the tool on 35 firms and modifying certain categories, firms with more than one employee drawn from Dun \& Bradstreet international database received the questionnaire. 241 entrepreneurs and top level managers accepted to collaborate. Mann Whitney's test did not identified remarkable difference across non-responded or early-late response ( $\mathrm{p}$-value<.1), showing no bias. Additionally, Harman's sigle factor test discarded common method bias. Exploratory factor analysis revealed 3 factors with eighenvalues greater than one, and no single factor accounted more than $25 \%$ of the co-variation.

Classified according to size, 56.2\% of the firms had less than 6 employees, 
$33.8 \%$ had between 6 and 24, and 10\% had more than 24. The sample shows low average values in terms of Product design intensity (Mean $=5.87 ; \mathrm{Sd}=5.86$ ), and Marketing intensity (Mean $=2.23 ; \mathrm{Sd}=3.63$ ). Regarding product innovation, $48.1 \%$ of the firms ranged from medium to very low product innovativeness; while $46.6 \%$ of the firms belong in the medium to very low market segments. Finally, the averge number of trade shows attended per year was $2.4(\mathrm{Sd}=2.42)$.

Table 1 here.

\subsection{Variables}

\subsubsection{Innovation performance}

Following Hervas-Oliver and Albors-Garrigos (2009), the dependent variable was built mixing data from two sources: a) manager's perception about firm's product innovation evaluated through a 5 point Likert scale; b) firm's market positioning evaluated through the final price of the product using a 5 point Likert scale. A reliability analysis revealed a satisfactory Cronbach's alpha of 0.70. A factor analysis $(\mathrm{KMO}>$ $0.50 ;$ p-value $<.01)$ yielded one factor explaining $65.29 \%$ of the variance and loading equal 0.80 .

\subsubsection{Vertical relationships}

This variable measures permanent collocation's effect. Respondents rated: a) the strategic relevance of the different linkages with clients and suppliers inside the cluster; b) the stability and intensity of the resources shared among each type of intra-cluster relationship. We applied a 5-point Likert scale where 1: very low and 5: very high. Internal validity and consistency of the construct was proven by a Cronbach's alpha

over .85 . This result validates the aggregation of the four items in one factor evidencing 
eigenvalue $=2.74$ and $68.42 \%$ of the variance explained $(\mathrm{KMO}>0.50 ; \mathrm{p}$-value $>.01)$. Factors loadings ranged from 0.78 to 0.877 .

\subsubsection{Internal resources}

To gather data about a firm's internal innovation activities, the survey asked about product design, development innovation intensity, and marketing innovation intensity. Considering Marsili and Salter (2006), the variable was operationalized considering percentage of design-product development and marketing expenditures on total sales during the previous three years.

\subsubsection{Extra-cluster temporary proximity}

Considering above mentioned literature (Ramírez-Pasillas, 2008, Torre, 2008), international exhibitions and trade shows represent contexts of temporary proximity as face-to-face interactions during the event multiply the occasions of knowledge sharing through formal and informal channels. The average number of international exhibitions and trade shows attended by the firm during the previous three years constitutes the proxy for temporary clusters. To avoid relying in just indicator, data on trade shows was combined with average export intensity during the previous three years, assuming that higher export intensity implies more pro-active attitude in the attended events. Factor analysis provided a unique factor evidencing eigenalue $=1.27$ and $63.467 \%$ of the variance explained $(\mathrm{KMO}>0.500$ and $\mathrm{p}$-value $<.01)$. Factor loadings accounted for 0.797 .

\subsubsection{Control variable}


Firm's size measured the average number of employees during the previous three years. Size can affect a unit's innovation becauselarge units have more resources and advantages in gaining support for its innovation activities.

A qualitative confirmatory analysis further verified the strength of the variables. Peer debriefing (confirming analysis with a small group of academic experts and policy makers) and member checks (confirming analysis with the study's participants) also corroborated the validity of the construct. Table 1 shows operativization and Table 2 shows main descriptive statistics, and correlation matrix.

Table 2 here.

\subsection{Statistical analysis and results}

To overcome several statistical problems (e.g. non-normally distributed variables), bootstrapping non-parametric technique was applied to evaluate strength and significance of the indirect effect. Further than the mere analysis of whether Internal resources mediate the effect of vertical relationships on innovation performance, this study proposes a moderated mediation model of vertical relationships, Internal resources, Temporary proximity and Innovation performance. Moderated mediation occurs when a mediated relationship depends on the level of a moderating variable. In the model depicted in Figure 1, internal resources mediate the association between vertical relationships and innovation performance, and the strenght of this mediated relationship varies depending on temporary proximity.

To test vertical relationships' effect on innovation performance, Preacher et al.'s (2007) method implementation tests the conditional indirect effect at the mean level of temporary proximity and at one standard deviation above and below the mean in the moderator. Considering its aim, this study first obtained the mediator variable model: 
internal resources were regressed on vertical relationships and the interactions for the moderating effects (Vert*TemProx). The interaction term Vert*TemProx was significant at $\mathrm{p}$-value $<.05$. Next, the dependent variable model was calculated: innovation performance was regressed on vertical relationships, internal resources, and the interactions for the moderating effects (Vert*TemProx and InRec*TemProx). Table 3 shows that the interaction IntRec*TemProx was significant at p-value $>.01$.

Table 3 here.

According to results displayed in Table 3, the indirect effect was significant at one standard deviation above the mean in temporary proximity (boostrap indirect effect $=0.88 ; \mathrm{p}$-value $<.1)$. Conversely, the indirect effect was not significat at the mean level of the moderator (boostrap indirect effect $=-0.03$; p-value $>.1$ ) and at one standar deviation below the mean in temporary proximity (boostrap indirect effect $=-0.95$; value $>$.1). Among firms engaged in higher temporary proximity, vertical relationships are associated with better innovation performance through higher internal resources. In addition, there is not mediated relationship between vertical relationships, internal resources, and Innovation performance in lower and average temporary proximity.

In a final procedure, the indirect effect's region of significance was obtained using the values of the moderator for which the mediation effect was significant. Figure 2 shows the magnitude of the conditional indirect effect at different $z$-values of the moderator with a $90 \%$ confidence band. The two dotted lines represent the lower and upper boundaries of the region of significance.

Figure 2 here. 


\section{Discussion and conclusion}

Using firm-level data from the largest Spanish footwear cluster and a innovative methodology, this study provides valuable insights on the crucial role of geographical proximity, either temporary or permanent, for innovation. The findings indicate that intra-cluster linkages foster innovation through internal resources. However, the effectiveness of this mediating mechanism depends on the moderating effect of the extra-cluster temporary proximity. In other words, only firms with certain levels of both temporary and permanent proximity acquire the external resources that sustain innovation. Consequently, the fashionable hypothesis of the death of distance should be reconsidered, and irrelevance of geographical proximity for knowledge transfers and innovation should be carefully re-examined.

As Rallet (2008) indicates, the role of space has changed but is not negligible. Although proximity has become more and more temporary and restricted to certain moments, face to face interations still create opportunities for tacit knowledge transmission, and innovation. Additionally, the particular profile of both forms of proximity confirms the need for the "global" and the "local". Firms need a minimum threshold of extra-cluster relationships to maximize the benefits of intra-cluster linkages absorbed thanks to firms' solid internal resources. Practitioners and policy makers should promote certain temporary proximity because it provides opportunities for knowledge transfers (particularly fine grained) that complement local knowledge, generating valuable synergies.

Findings show that temporary proximity does not displace permanent proximity.

Consistently with nowadays business dynamics, temporary and permanent proximity should complement each other to optimize innovation activities. First, because 
traditional intra-cluster sources of knowledge, particularly customers and suppliers, are not longer strictly local. Second, because the increasing specialization of some clusters demands concise knowledge not provided by local institutions. Counterbalancing some previous research (Lagendijk \& Lorentzen, 2007), the benefits derived from territorialized partners and permanent proximity remain crucial, but these elements should be combined with certain forms of temporary geographical proximity.

The form of temporary proximity selected allows some interesting final considerations. On the one hand, trade shows should not be only viewed as opportunities for developing commercial and internationalization aspects, but also as powerful tools to acquire valuable knowledge or enhance inter-organizational social capital that fosters firms' innovation performance. The multi-level knowledge exchanges in these temporary forms of proximity - from the merely local to the truly global - activate diverse synergies that stimulate innovation (Rinallo \& Golfetto, 2011). Therefore, organizers should design innitiatives to further expand this interacting facet between highly internationalized and specialized groups. Additionally, complementing Tafesse and Korneliussen (2012), firm managers managers assigned to the event objective setting, selection decision, and implementation should acknowledge the crucialness of foreing events for both marketing and the acquisition of knowledge to innovate. On the other hand, trade shows amplify the positive effect of permanent proximity because attending firms may observe latest trends and novel technologies or engage in collective promotion of their activities (Ramirez-Pasillas, 2010). From the systemic perspective, firms may help other local units to surpass well-known detrimental effects derived from permanent geographical proximity by disseminating inside the cluster boundaries. 


\section{Promotional events and innovation in clusters}

Finally, the particular operativization of the variables or the cross-sectional and specific nature of the sample require caution in interpreting these results (particularly regarding generalizability). Future research should try to overcome these limitations by evaluating other forms of temporal proximity and multi-sectorial and longitudinal data. 


\section{References}

Asheim, B. \& Isaksen, A. (2002). Regional Innovation Systems: The Integration of Local 'Sticky' and Global 'Ubiquitous' Knowledge. Journal of Technology Transfer, 27, 77-86.

Autant-Bernard, C., Mairesse, J. \& Massard, N. (2007). Spatial knowledge diffusion through collaborative networks. Papers in Regional Science, 86, 495-519.

Bathlet, H., Malmberg, A. \& Maskell, P. (2004). Clusters and knowledge: Local buzz, global pipelines and the process of knowledge creation. Progress in Human Geography, 28, 31-56

Bathelt, H. \& Schuldt, N. (2008). Between luminaires and meat grinders: International trade Fairs as temporary Clusters. Regional Studies, 42, 853-868.

Boschma, R. (2005) Proximity and innovation: A critical assessment, Regional Studies, $1,61-74$.

Camagni, R. (1991). Local “Milieu," Uncertainty and Innovation Networks: Towards a New Dynamic Theory of Economic Space. In Camagni, R. (ed.) Innovation Networks: Spatial Perspectives, 121-142. London: Belhaven Stress.

Cohen, W. \& Levinthal, D. (1990). Absorptive Capacity: A New Perspective on Learning and Innovation. Administrative Science Quarterly, 35, 128-152.

Geigenmüller, A. (2010). The role of virtual trade fairs in relationship value creation, Journal of Business \& Industrial Marketing, 25, 284-292

Giner, J. \& Santa María, M. (2002). Territorial systems of small firms in Spain: an analysis of productive and organizational characteristics in industrial districts, Entrepreneurship and Regional Development, 14, 211-228.

Giuliani, E. \& Bell, M. (2005). The micro-determinants of meso-level learning and innovation. Evidence from a Chilean wine cluster. Research Policy, 34, 47-68. 
Hervas-Oliver, J. \& Albors-Garrigos, J. (2009) The role of the firm's internal and relational capabilities in clusters: When distance and embeddedness are not enough to explain innovation. Journal of Economic Geography, 9, 263-283.

Lagendijk, A. \& Lorentzen, A. (2007). Proximity, Knowledge and Innovation in Peripheral Regions. On the Intersection between Geographical and Organizational Proximity. European Planning Studies, 4, 457-466.

Ling-yee, L. (2006). Relationship learning at trade shows: Its antecedents and consequences. Industrial Marketing Management, 35, 166-177.

Lorentzen, A. (2007). The geography of knowledge sourcing: A case study of polish manufacturing enterprises. European Planning Studies, 15, 467-486.

Markusen A. (1996). Sticky places in slippery space: a typology of industrial districts. Economic Geography, 72, 293-313.

McCann, B. \& Folta, T. (2011). Performance differentials within geographic clusters. Journal of Business Venturing, 26, 104-123.

Palumbo, F. \& Herbig, P. (2002) Trade shows and fairs. Journal of Promotion Management, 8, 92-108.

Preacher, K., Rucker, D. \& Hayes, A. (2007). Addressing moderated mediation hypotheses: Theory, methods, and prescriptions. Multivariate Behavioral Research, 42, 185-227.

Ramirez-Pasillas, M. (2010). International trade fairs as amplifiers of permanent and temporary proximities in clusters. Entrepreneurship and Regional Development, 22, 155-187

Ramirez-Pasillas, M. (2008). Resituating proximity and knowledge cross-fertilization in clusters by means of International trade fairs. European Planning Studies, 16, 643-663. 
Rinallo, D. \& Golfetto, F. (2011). Exploring the knowledge strategies of temporary cluster organizers: A longitudinal study of the EU fabric industry trade shows (1986-2006). Economic Geography, 87, 453-476

Rychen, F. \& Zimmermann, J. (2008). Clusters in the global knowledge based economy: Knowledge gatekeepers and temporary proximity. Regional Studies, 42, $767-776$

Tafesse' W. \& Korneliussen, T. (2012). Managing trade show campaings: Why managerial responsabilities matter? Journal of Promotion Management, 236-253

Tanner, J. \& Chonko, L. (2002). Using trade shows throughout the product life cycle. Journal of Promotion Management, 8, 109-125

Torre, A. (2008). On the role played by temporary geographical proximity in knowledge transmission. Regional Studies, 42, 869-889.

Wolfe, D. \& Gertler M. (2004). Clusters from the inside and out: Local dynamics and global linkages. Urban Studies, 41, 1071-1093.

Wood E. (2009). Evaluating event marketing: Experience or outcome. Journal of Promotion Management, 15, 247-268. 
Table 1. Operationalization

\begin{tabular}{|c|c|}
\hline Variables & Description \\
\hline Innovation performance & $\begin{array}{l}\text { Data from: a) perception about firm's } \\
\text { product innovation; b) market } \\
\text { positioning evaluated through the final } \\
\text { price of the product ( } 5 \text { point Likert } \\
\text { scale) during the last three years. }\end{array}$ \\
\hline Size & $\begin{array}{l}\text { The average number of employees } \\
\text { during the previous three years. }\end{array}$ \\
\hline Internal resources & $\begin{array}{l}\% \text { design-product development and } \\
\text { marketing expenditures on total sales } \\
\text { during the previous three years. }\end{array}$ \\
\hline Vertical relationships & $\begin{array}{l}\text { Measures permanent collocation. Data } \\
\text { from: a) the strategic relevance of } \\
\text { linkages with local clients and } \\
\text { suppliers; b) the stability and intensity } \\
\text { of the resources shared ( } 5 \text { point likert) } \\
\text { during the last three years. }\end{array}$ \\
\hline Temporary proximity & $\begin{array}{l}\text { Combined data on: a) Average number } \\
\text { of international trade shows attended }\end{array}$ \\
\hline
\end{tabular}


Promotional events and innovation in clusters

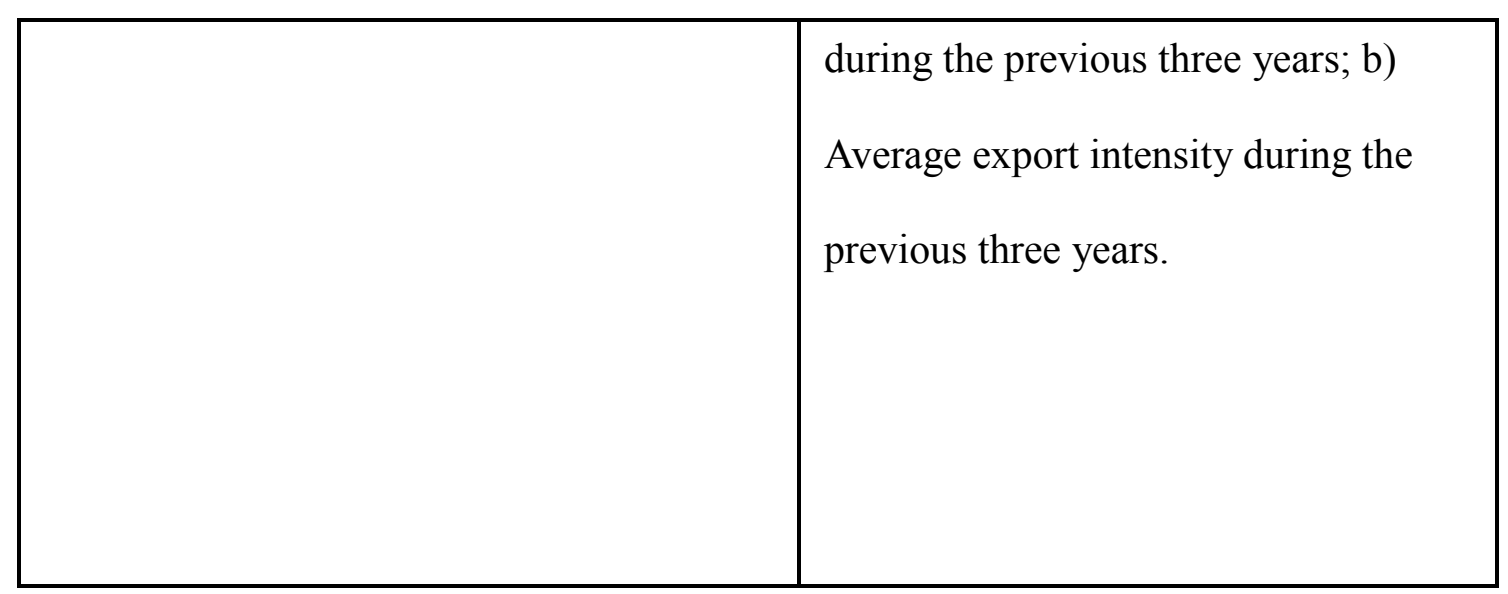


Promotional events and innovation in clusters

Table 2. Correlations and main descriptive statistics

\begin{tabular}{|l|rrrrr|}
\hline Innovation performance & 1 & & & & \\
Size & $* * * .226$ & 1 & & & \\
Internal resources & $* * 0.117$ & 0.056 & 1 & & \\
Vertical relationships & 0.083 & -0.010 & $* 0.092$ & 1 & \\
Temporary proximity & 0.096 & $* * * .349$ & $* * 0.201$ & $* * * 0.150$ & 1 \\
\hline Mean & 0.000 & 11.69 & 4.079 & 0.000 & 0.000 \\
Standard deviation & 1.000 & 17.91 & 3.499 & 1.000 & 1.000 \\
\hline
\end{tabular}

Significance level ***.01; **.05; *.1 
Promotional events and innovation in clusters

Table 3. Moderated mediation model results

\begin{tabular}{|l|c|c|}
\hline Constant & Mediator variable model & Dependent variable model \\
Size & $* * * 3.9924$ & $* *-0.2084$ \\
Vertical & $* * *-0.8967$ & $* * 0.3146$ \\
Relationships & 0.1655 & 0.0501 \\
Temporary & $* * 3099$ & -0.1164 \\
proximity & & -0.1442 \\
Vert $*$ TemProx & $* 012$ & $* * * 0.0482$ \\
\hline Internal Resources & & $* * * 0.0520$ \\
IntRec $*$ TemProx & -0.9833 & \\
\hline Conditional indirect effect at specific value(s) of the moderator(s) \\
\hline Mean -1SD
\end{tabular}

Significance level $* * * 0.01 ; * * 0.05 ; * 0.1$ 
Figure 1. Compacted presentation of the conditional indirect model

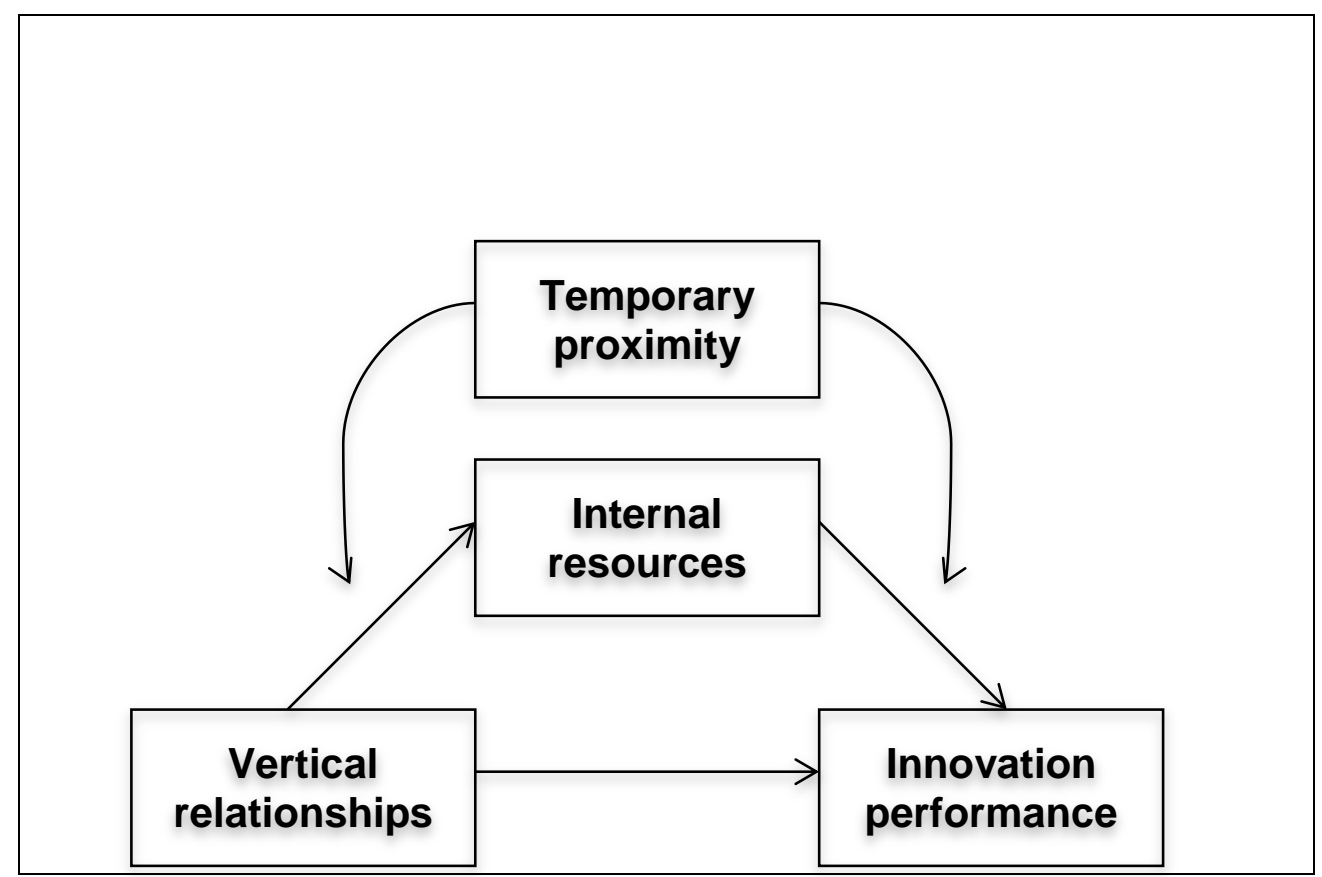


Promotional events and innovation in clusters

Figure 2. Region of significance at different levels of the moderator

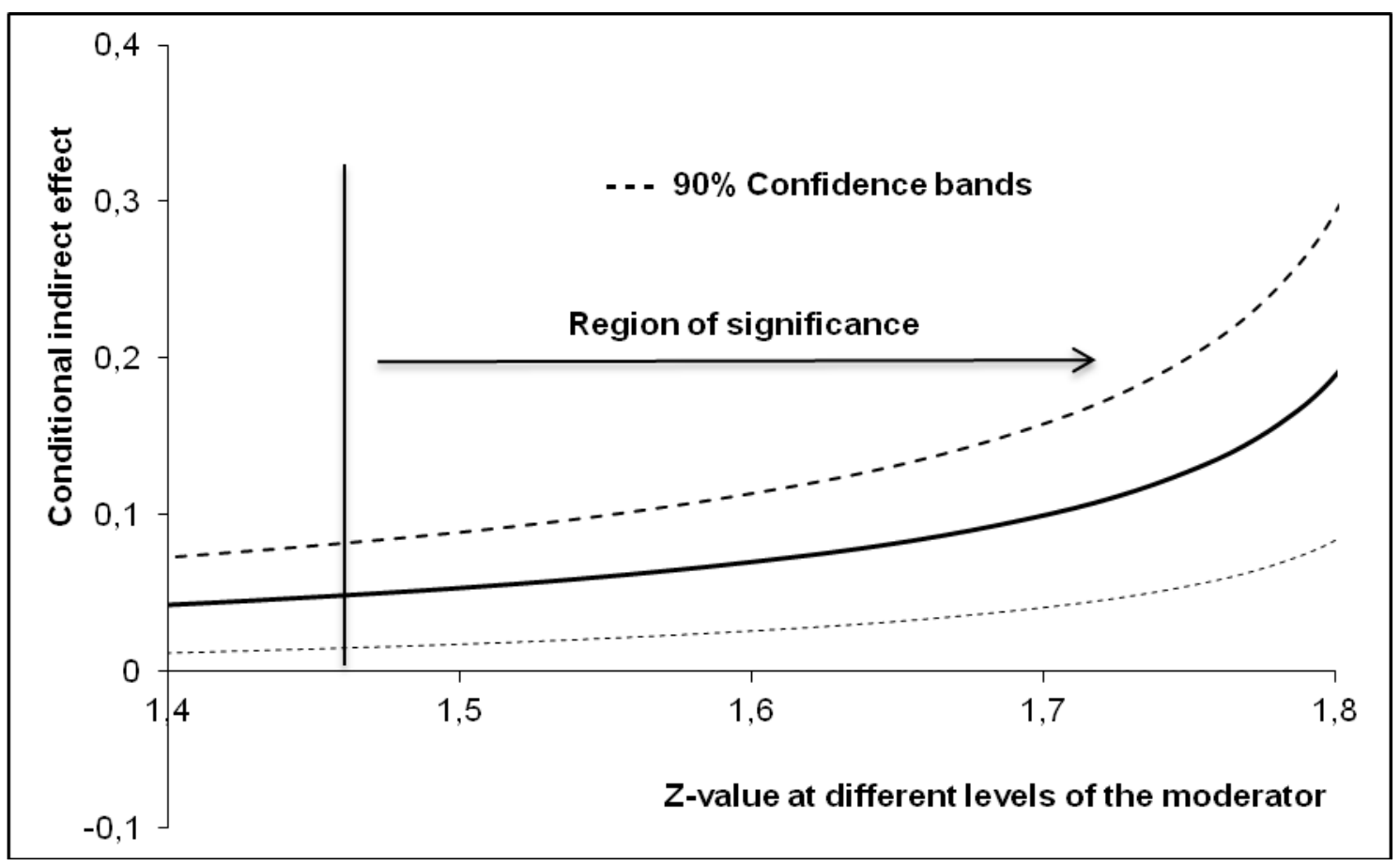

